\title{
A Step Towards Including Children's Evacuation Parameters and Behavior in Fire Safe Building Design
}

\author{
ALDIS RUN LARUSDOTTIR, and ANNE S. DEDERICHS \\ Department of Civil Engineering \\ Technical University of Denmark \\ Brovej, Building 118, 2800 Kgs. Lyngby, Denmark
}

\begin{abstract}
An important part the world's population is neglected in today's fire safety design - children. The vast amounts of data as well as the empirical models applied describe adults. This paper embraces the fact that there is a difference between children and adults, regarding evacuation and that children's movement parameters are age dependent. On the basis of 16 full-scale evacuation experiments made in 10 Danish daycare centers the present paper gives input data applicable in fire safety design on flow through doors, walking speed in horizontal plane and spiral stairs. Parameters distinguish small children in the age of $0-2$ years from older ones in the age 3-6 years. An empirical model of children's flow through doors is introduced. The effect of using alarm/warning system on pre-evacuation time is briefly discussed. Behavioral aspects are also considered where possible. It is found that there is a higher need of physical assistance during evacuation for children in the age of 0-2 years, than for children aged 3-6. Children aged 3-6 years are keen to run during evacuations. Furthermore it was observed that children are used to following rules and routines which they continue doing during the evacuation. At last the effect of affiliation during the evacuation was seen among the children.
\end{abstract}

KEYWORDS: egress, children, flow, occupant density, human behavior.

\section{INTRODUCTION}

The population of the western world comprises of between 15 and $20 \%$ children aged $0-14$ years [1,2]. However, information on this part of the population is often neglected in fire safety design even in case of school buildings [3]. Buildings should be safe for all occupants whether they are designed according to prescriptive fire codes or performance-based codes. Building traditions, materials and technology have changed drastically throughout decades, forcing fire safety design to keep up. However, the fire society's main focus of new measures lays on the technical design focusing on the physics of the fire and the buildings rather than on the human beings which are to be protected. Many drastic changes to regulations and practice have been made after large fires, were valuable lessons were learned [4,5]. Important information on the subject has also been collected throughout studies and experiments, which all together are the fundamentals of today's fire safety design.

When designing new buildings and applying performance-based codes it is important to have an understanding of human evacuation dynamics as well as having access to performance models which account for a broad population in order to reduce the risk of exposing occupants to critical conditions in case of fire. The existing literature provides a number of case studies on real fire incidents as well as experiments concerning fire and evacuations $[1,5,6]$. However, they provide design parameters and models on walking speed in horizontal plan and in stairs and flow through doors as well as other aspects relevant for evacuation. The results are applied in models and introduced in simulation programs for prediction of the evacuation process. The majority of previous studies deal with the evacuation behavior of adults where users are expected to be able to bring themselves to safety in case of an evacuation [1]. These include studies on evacuation dynamics in private, public, and commercial buildings with different occupational hours, where the evacuees are either familiar or unfamiliar with the building [6-16]. However in recent years studies have focused on a broader population for experiments and models. For instance by considering people with disabilities and other groups that might require assistance during an evacuation [17-21].

Another aspect is that society has developed through time in many ways. One is that it is more and more common for both parents having a working career outside of the home. This means that more children and younger children are in daycare centers during the day. Still few studies exist on evacuation of young 
children, such as daycare centers or other places were a large number of children are located [1,22-24] Hence, there exists very little data and no model describing walking speeds, flow or densities particularly of children of this young age.

The aim of this paper is to bring the fire safety community a step closer to including children in fire safety design, by introducing movement parameters and an empirical model describing evacuation of young children. Attention is also brought to the difference between adults and children, when it comes to evacuation. Behavioral aspects are investigated and discussed to increase the understanding of children's evacuation dynamics and therefore contribute to safer buildings for children. The parameters investigated are velocities and flow on stairs and through doors as well as the relevance on automatic fire alarms, and the need of aid during the evacuation. It shall be seen whether the current data on adults is conservative enough to keep children safe in buildings.

\section{METHOD}

The data presented in this paper are the results from a study on fire evacuations of Danish daycare centers. It is not obligatory to have fire drills in daycare centers in Denmark. Hence, this was the first time for many of the daycare centers to perform a full-scale evacuation. In fact, the fire drill was a first time experience for all children which were currently enrolled in the daycare centers and many of the staff. Ten daycare centers all located in Lyngby municipality, a suburb of Copenhagen, participated in full-scale evacuation experiments. Four daycare centers performed the experiment twice and one performed the experiment three times involving a total of 1017 persons, where 268 evacuated twice and 67 three times. The experimental period was from March to May and November 2009. Danish daycare centers host two age groups, "younger children" aged between 6 months and 2 years and "older children" aged 3-6 years.

All in all there were performed sixteen full-scale evacuation experiments, in the form of fire drills. The evacuations were filmed in order to collect data; other forms for data collection were interviews with staff, time taking, measurements and observation on site. The fire drills were more or less unannounced for the children, but most of the daycare centers staff was prepared.

The course of action was typically:

- Arriving at the daycare center and talking to the contact person.

- Setting up cameras, focusing on the exits.

- Turning the cameras on, one by one.

- Fire drill starts, fire alarm/verbal warning.

- Evacuation to outside.

- Gathering at assembly point, waiting for "all clear".

- Discussing the fire drill with the older children.

In order to make fire safety design cover children and daycare centers, the relevant evacuation characteristics for the group need to be described. The goal of this study is to deliver empirical relevant design parameters as well as a few guidelines to consider in fire safety design for children.

Most of the data was collected using cameras, the basic set-ups and measurement techniques will now be briefly described. The recorders were partially exposed and out of reach for the children.

The densities measured during the flow measurements are local person densities in front of the doors, where tape markings or standard size mats were used as reference. Each measuring point marks a continuous flow of 6-51 people, which occurred during the experiments. The walking and running speeds were calculated by measuring the time it took children to pass fixed points. A child was defined as running if both feet left the ground simultaneously.

The travel speed on the three spiral stairs was calculated by measuring the length of the travel path and dividing with the time each person spend on the staircase. The travel speeds on spiral stairs are therefore individual averages, where fluctuations within the stair are neglected.

The films were analyzed for walking speed in horizontal plane and spiral stairs and flow through doors as described above as well as behavioral pattern. In general it must be stated that more data is necessary to 
prove statistical validity. Hence the results presented in this work are not general, but indicate trends. The data and model refer to homogeneous population of children only.

\section{RESULTS AND DISCUSSION}

The results presented in this section give information on flow through doors, walking speed in a horizontal plane and spiral stairs. An empirical model is developed, which enables the description of flow through doors. In Danish daycare centers children are divided into the two age groups, 0-2 years and 3-6 years. This enabled a separation of the results describing these two age groups.

\section{Flow Through Doors - Empirical Model}

The flow through doors is presented in Fig. 1. The boxes mark measuring points for the older age group, aged 3-6 years and the circles mark the measuring points for the younger children, aged $0-2$ years. Trend lines for each of these measurement series are also plotted as well as Nelson and Mowrer's widely used flow curve for comparison [7].

It can be seen in Fig. 1 that for the older children the highest flow measured in a single measurement was above 3 pers $/ \mathrm{s} \mathrm{m}$ at a person density 5 pers $/ \mathrm{m}^{2}$, but the trend line peaks at a person density around 8 pers $/ \mathrm{m}^{2}$ with a flow of around 2.5 pers $/ \mathrm{s} \mathrm{m}$. For the younger children the highest flow measurement was also made at a person density 5 pers $/ \mathrm{m}^{2}$ but here the flow was just above 1.5 pers $/ \mathrm{s} \mathrm{m}$ and here the trend line has a peak with a flow of around 1.25 pers $/ \mathrm{s} \mathrm{m}$ at a person density of approximately $6.5 \mathrm{pers} / \mathrm{m}^{2}$.

For the age group 3-6, adults were rarely a part of the measured flow, because the children were in most cases eager to evacuate and the staff waited until last to exit. However more adults evacuated among the children aged 0-2 years, since many needed assistance and guidance. There are also more adults caring for the younger children on a daily basis. When comparing to Nelson and Mowrer's flow curve it is clear that the older children exceed that curve while the younger children do not. This comparison does not take into account different sizes of people, the fact that physically there can be more children located in one square meter than adults.

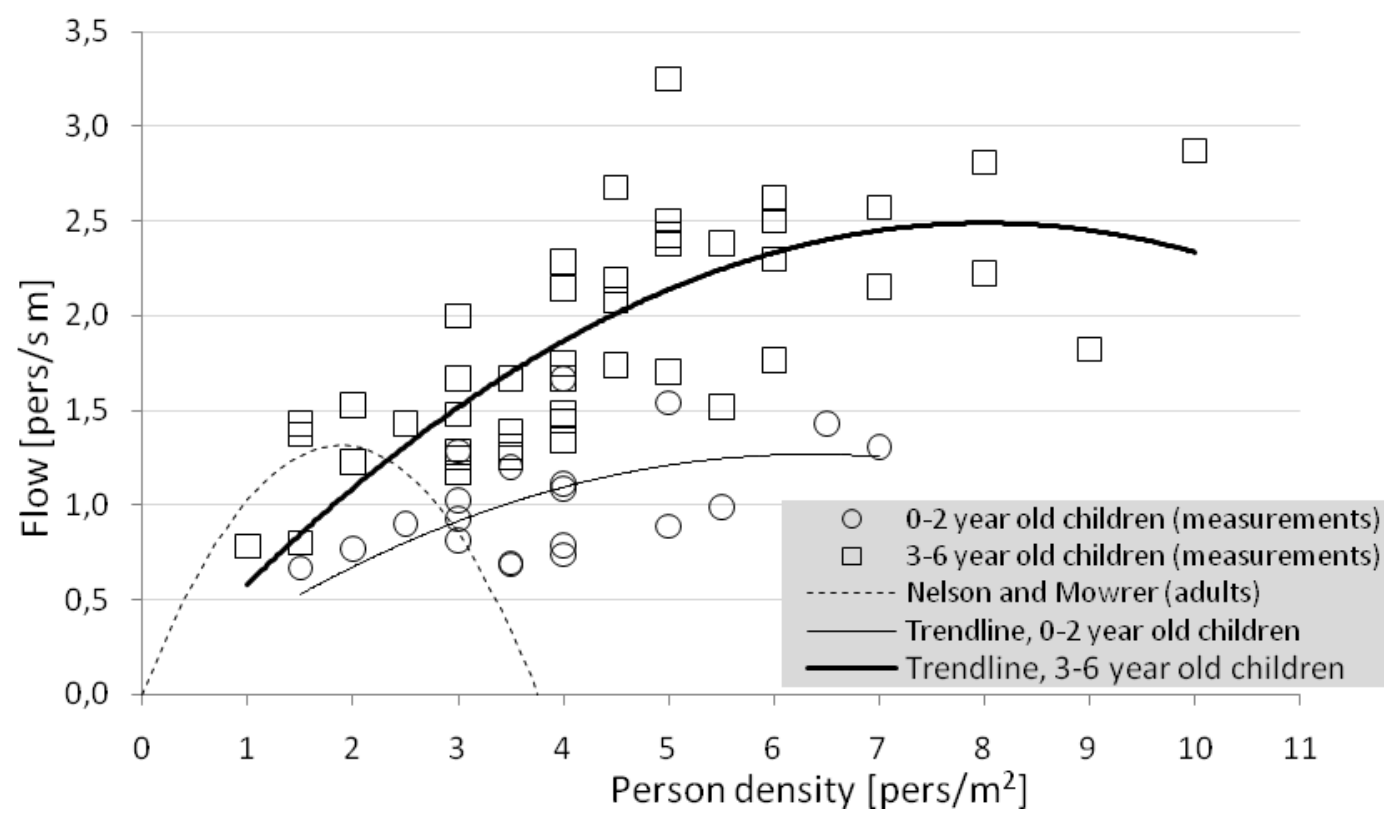

Fig. 1. Flow through doors. Mesurements on children [1] and their trendlines, compared to Nelson and Mowrer's flow curve [7].

Nelson and Mowrer's flow curve has been published in numerous handbooks and other relevant publications on fire safety $[7,25]$ where flow in the unit pers/s per meter effective width is shown with respect to person density in the unit pers $/ \mathrm{m}^{2}$. This formulation applies to homogenous populations only. Due to the nature of daycare centers, there will always be some adults among the children when evacuating 
and the results on flow presented in Fig.1 include 5-10\% adults for the older children and 20-30 \% adults for the younger children. Even though populations (size wise) cannot be mixed using the approach above, it is more adaptive and easier to relate to than the correlations by Predtechenskii and Milinskii [16].

Concerning the effective width of the doors, it could be seen from the recorded material that the whole free width of the door was used when needed, so the door width was not reduced in the flow calculations, as if there was a boundary layer.

The trend lines shown in Fig. 1 can be expressed by second degree polynomials (Eq. 1) with a fixed intersection at 0.0. The polynomial follows the expression of the SFPE Handbook [7]. Values relevant for age group 0-2 and 3-6 could be found for the constants $a$ and $k$. Equation 1 gives the relation between the specific flow, $F_{S}$, in pers/s and person density, $D$, in pers $/ \mathrm{m}^{2}$ for the two age groups. The equations for the trend lines are found by inserting $a_{0-2 / 3-6}$ and $k_{0-2 / 3-6}$ respectively.

$$
F_{s}=(1-a D) k D
$$

where:

$\begin{array}{ll}a_{0-2}=0.079 & a_{3-6}=0.062 \\ k_{0-2}=0.622 & k_{3-6}=0.399\end{array}$

The presented model is more conservative than the model of Nelson and Mowrer's flow curve for a density below 3 pers $/ \mathrm{m}^{2}$.

\section{Movement Parameters}

The results of the movement parameters found in the current study have been gathered and Table 1 shows an overview of those.

The flow was discussed in the previous section but is included in Table 1 to complete the overview. Walking speeds were measured in the horizontal plane at low person densities $\left(<0.5 \mathrm{pers} / \mathrm{m}^{2}\right)$, where the children could move freely and independently of others. This also applies for the running measurements. Three spiral stairs were analyzed, and the results for all three are included in Table 1.

Table 1. Parameters for children's movement during evacuation.

\begin{tabular}{|l|l|c|c|c|c|c|c|c|c|}
\hline Parameter & \multicolumn{3}{|c|}{ Children 0-2 years } & \multicolumn{4}{c|}{ Children 3-6 years } \\
\hline \multicolumn{2}{|l|}{ Flow (pers/s) } & \multicolumn{3}{c|}{$0.031 D^{2}+0.399$} & \multicolumn{4}{c|}{$0.039 D^{2}+0.622 D$} \\
\hline \multirow{4}{*}{} & $\begin{array}{c}\text { Mean } \\
(\mathrm{m} / \mathrm{s})\end{array}$ & $\begin{array}{c}\text { Min. } \\
(\mathrm{m} / \mathrm{s})\end{array}$ & $\begin{array}{c}\text { Max. } \\
(\mathrm{m} / \mathrm{s})\end{array}$ & $\begin{array}{c}\text { SD } \\
(\mathrm{m} / \mathrm{s})\end{array}$ & $\begin{array}{c}\text { Mean } \\
(\mathrm{m} / \mathrm{s})\end{array}$ & $\begin{array}{c}\text { Min. } \\
(\mathrm{m} / \mathrm{s})\end{array}$ & $\begin{array}{c}\text { Max. } \\
(\mathrm{m} / \mathrm{s})\end{array}$ & $\begin{array}{c}\text { SD } \\
(\mathrm{m} / \mathrm{s})\end{array}$ \\
\hline \multirow{3}{*}{ Walking } & Plane & 0.60 & 0.30 & 0.98 & 0.17 & 0.84 & 0.42 & 1.36 & 0.25 \\
\cline { 2 - 10 } & Stair 1 & - & - & - & - & 0.58 & 0.25 & 1.40 & 0.31 \\
\cline { 2 - 10 } & Stair 2 & - & - & - & - & 0.38 & 0.29 & 0.48 & 0.07 \\
\cline { 2 - 10 } & Stair 3 & - & - & - & - & 0.13 & 0.08 & 0.33 & 0.06 \\
\hline Running & Plane & 1.14 & 0.90 & 1.80 & 0.30 & 2.23 & 0.83 & 3.24 & 0.64 \\
\hline
\end{tabular}

A frequently used values used for adults' average walking speed in a horizontal plane at low person densities is $1.2-1.3 \mathrm{~m} / \mathrm{s}[8,25]$. Compared to the children's movement speeds presented here it can be stated that adults move faster. This difference can be linked to the body's proportions, as well as general physical development. However, Table 1 shows that when the older children run they exceed the common average walking speeds for adults, mentioned above.

Not all children in the younger age group were able to walk by themselves; hence fewer measurements were available for that age. This especially applies for running, since children cannot be expected to run efficiently until around age 2 or 3 [24]. The movement speed of children carried by adults or holding an adult's hand was excluded in this analysis, since in that case the child does not move freely and independent of others. 
To give a better understanding of the results on the spiral stairs the three stairs will be briefly described. Stair 1 is an internal stair used by the children daily. It also has an extra handrail at a height for the children. The depth of the steps (tread) in the walking path is $0.29 \mathrm{~m}$ and the height (rise) of each step is $0.19 \mathrm{~m}$. Stair 2 is a spiral stair in a square stair case in an old house. The children do not use the stair regularly and the stair only has an inconvenient handrail in the center. The dimensions of the steps in the walking path are the same as for Stair 1. Stair 3 is a typical metallic external fire escape, where the steps are see-through. The children had never used the stair before the experiment and the handrail is high and hard to reach for the children. The depth of the steps (tread) in the walking path is $0.29 \mathrm{~m}$ as for Stairs 1 and 2 but the height (rise) of each step is $0.17 \mathrm{~m}$, making the slope slightly less steep compared to the other two stairs. The walking path was defined $0.25 \mathrm{~m}$ from the wider end of the stair.

Table 1 shows a remarkable difference in the movement speed on the stairs, despite their similar dimensions. The highest speeds were obtained in Stair 1, the stair frequently used by the children and with an extra handrail. This indicates that the children's familiarity of the stair and the stairs' child-friendly design, affected the movement speed to the better. This is supported by the extremely low speeds measured in Stair 3 which the children were using for the first time and was not specially designed for children. The difference in variation can also be seen in Table 1. Again Stair 1 stands out with a high standard deviation. The recordings revealed that the first children rushed down the stair at very high speeds, but as more children gathered in and by the stair the movement speed dropped. Both Stair 2 and Stair 3 have a more steady movement speed, which is reflected in the low standard deviation.

A general average value for adults, travelling on spiral stairs of $0.5 \mathrm{~m} / \mathrm{s}$ is suggested [25], nondependent on the width of the stair [10]. The width is not relevant since persons usually walk in a single row in spiral stairs, because of the narrow steps near the center. This was confirmed in this study; although a few passes were made when a child stopped in the middle of a stair.

When comparing the results presented in Table 1 to the known literature for adults it can be seen that the children generally move slower than adults.

The high movement speeds achieved on Stair 1 and the slow speeds on the other two stairs supports the conclusion of Murozaki's and Ohnishi's study [23], which states that familiarity with the evacuation route is a leading factor to a achieve a fast evacuation.

\section{The Effect of Alarm System on Pre-evacuation Time}

The effect of automatic fire alarm on pre-evacuation time was studied, that is the time from "detection" until evacuation started. In this analysis the definition on when a person starts to evacuate is that when it leaves the current room, and is therefore clearly started to evacuate. This definition has been used when studying apartment buildings [6] and is convenient in this case, as the cameras were focused on the doors. Another advantage is that the definition is clear, and no interpretation is needed during the analysis on whether or not the movement is connected to the evacuation or not.

Figure 2 shows a box plot for the pre-movement times, where pre-movement times in daycare centers with an alarm/warning system can be compared to the pre-movement times in the daycare centers that do not have any. Having no alarm or warning system meant that an adult went around the daycare center and gave a verbal warning or a message to evacuate. In one case an internal phone system was used as aid, and in one case a small hand bell was used to get attention. These were categorized in the no alarm group, along with three other daycare centers. In three daycare centers a smoke detector was used for warning and those are categorized in the alarm group along with two daycare centers with automatic alarm and warning systems, who also call the fire department and close some doors.

The horizontal lines in the box plot represent the lower quartile $\left(25^{\text {th }}\right.$ percentile $)$, the median $\left(50^{\text {th }}\right.$ percentile) and the upper quartile $\left(75^{\text {th }}\right.$ percentile) respectively. The whiskers show the lowest/highest value still within 1.5 IQR (inter-quartile range) of respectively the lower/higher quartile. The outlier ( $\times$ mark) represents the maximum value since it is outside the range of the whisker. 


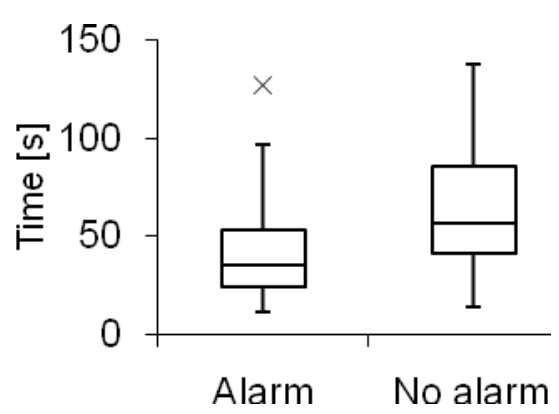

Fig. 2. A box plot showing the pre-evacuation time seperately for daycare centers with an alarm and without an alarm.

Figure 2 indicates that there is longer pre-movement time if no alarm or warning system is installed. The analysis revealed that the difference mainly lies in the warning time and not the reaction or decision making. The reason for this might be that in both cases (alarm or no alarm) an adult verbalized the evacuation signal. That is few children started to evacuate before verbally getting instructions on doing so from a nearby adult.

The size and design of the daycare center as well as the warning procedure itself were key factors in the total warning time, where there were no alarms. The pre-movement time varied also more as can be seen in Fig. 2, since some received the warning simultaneously with the start, while the ones located far from the initial starting point got a delayed warning. The maximum delay of warning registered in this study was $95 \mathrm{~s}$.

\section{Need of Assistance}

In this section the involvement of adults in the evacuation process is described. Fig. 3 presents the amount of assistance provided to the children during the evacuation, separately for the two age groups. The vertical axis shows the amount of children as a percentage and the horizontal axis shows the three different levels of assistance. The white boxes represent the younger age group and the gray boxes present the older age group.

There is a difference between the three levels of assistance. Some children were carried by an adult, which provides the most assistance available. Some received physical help, which includes handholding, gently pushing towards exit or assistance in steps or standing up, in fact all forms of physical help, except for carrying. The third level consisted of verbal commands only, which categorizes the children who evacuated after receiving verbal instruction on doing so but without any physical assistance.

Figure 3 shows a clear difference between the ages as mentioned earlier. While more than $80 \%$ of the older children evacuated without physical assistance only around $20 \%$ of the younger children did the same. This shows how important the adults are during evacuations of children.

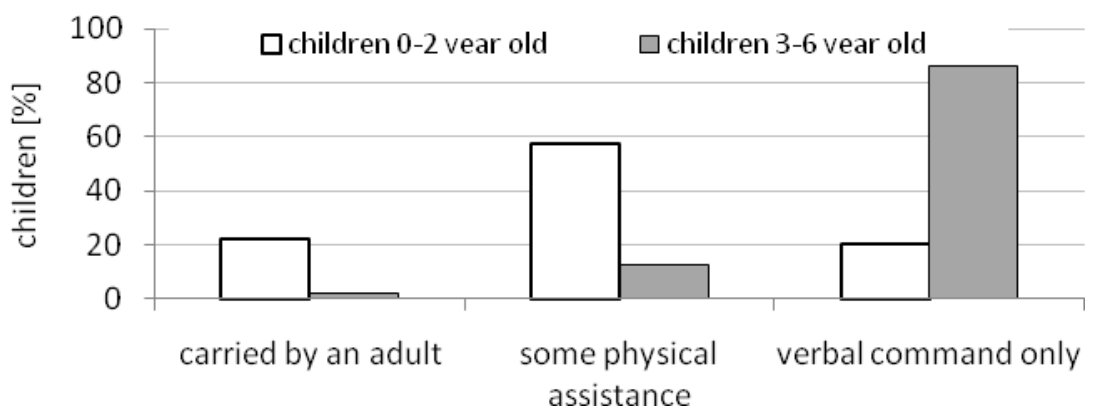

Fig. 3. Comparison of level of assistance during evacuation for the two age groups. Vertical axis: proportion of children in \%. Horizontal axis: three levels of assistance. 
The level of assistance during evacuation might be reduced with training. As mentioned earlier the evacuations made in this study, were the first fire drills the children participated in. The films showed cases where children most likely needed more assistance because they were not familiar with the evacuation procedure. In one case some children stood still after the fire alarm sounded, because they had never heard the alarm before. In another case a child was carried outside because it did not want to leave their favorite hat behind.

\section{Behavioral Considerations}

It was found that the two age groups (younger children aged 6 months to 2 years and older children aged 36 years) not only vary from each other when it comes to travel speed and flow through doors, but also when looking at the behavior. An example of a behavioral difference is that very few of the younger children ran during the evacuations (about $5 \%$ ) compared to the older children (about $40 \%$ ). This may be caused by several reasons. The recordings indicate that one factor might be that while the younger children were hesitating on evacuating, seeming a bit confused or surprised, many of the older children were excited and raced to the exits. However in some cases the children did not have the opportunity to run due to crowd or orders from the teachers on staying in line. It should also be noted that not all of the younger children were yet physically able to run, which also affects these numbers.

Another behavior that was noticed is that the children were keen to follow the rules and daily routines of their daycare center, during the evacuation, and some were reluctant to make exceptions. Some children started changing to outdoor shoes, others stopped in front of the door to zip up their coats. This also meant that most of the children obeyed the adults, without questioning their reasons. This form for role-rule model is likely at its strongest level, due to the young age of the children.

It was interesting to see other behaviors, known from general evacuation theory. Some children initially went for the main door of their group room, when receiving instructions on evacuating, even though the room had a direct exit to the outside. This is well known as affiliation theory, when people tend to use the evacuation paths and exits they are most familiar with, even though others might be closer or safer. There were also a few children who worried about their younger siblings, located elsewhere in the building. This behavior is seen where people will not evacuate without a family member, although in this case the children did not act on it, but only expressed their concern.

\section{CONCLUSION}

This paper presents an overview of characteristics relevant for children's evacuation, who in the long term can contribute to fire safety design guidelines and practice. The data was originally collected from sixteen full-scale evacuation experiments, in ten Danish daycare centers. The evacuations were filmed and analyzed to collect information on movement speeds in a horizontal plane and in spiral stairs as well as flow through doors. Assistance during the evacuations was also investigated as well as alarm system's effect on pre-evacuation time. Interesting findings were also made concerning the children's behavior during the evacuations.

All in all the results show that there is a difference between adult's movement characteristics and children's. Regarding the flow through doors, the children's flow exceeded Nelson and Mowrer's flow curve for adults, but only at person densities above $3 \mathrm{pers} / \mathrm{m}^{2}$. An empirical model is developed for the flow in a form of a second degree polynomial, describing the flow through doors. The equation has the same format as the equation for specific flow in the SFPE Handbook [7] but new values are provided for the constants, fitting it to either 0-2 year old children or 3-6 year old children.

Looking at movement speed in horizontal planes it can be said that children move slower than adults and that younger children move slower than older ones. When running, the children were however able to exceed the commonly average walking speed for adults. A large variation could also be seen in the dataset concerning the older children running. This can most likely be explained by the large variation in motor skills at that age, and the relatively large age gap. It can be concluded that the walking speed for children deviates from the data obtained and applied from literature.

The results on the movement speed on spiral stairs indicate that familiarity with the stair and the design of the stair greatly affects the speed. In the only stair which the children used on a daily basis and which had a special handrail for the children, the average travel speed exceeded the data from the literature on adults. 
The two other stairs had average travel speeds which were much lower than the speeds obtained from experiments with adults. The external metallic fire escape stair caused the children most problems, even though the slope in the walking path was slightly lower than in the other stairs.

The effect of alarm systems or warning systems on the pre-evacuation time was investigated. It was seen that a system of such kind decreased the pre-evacuation time.

The level of assistance was also analyzed and a great difference between the two age groups was discovered, showing that most of the children aged 3-6 years old evacuated on verbal command only while most of the children 0-2 were either carried or received other physical help.

When looking at the behavior one of the interesting findings was that there was a clear difference between the younger and older age groups during the evacuations. The older children ran much more frequently towards the exit than the younger ones. Behaviors known from evacuation theory could also be spotted among the children such as role-rule model and affiliation theory.

Coming back to Nelson and Mowrer's flow curve, which generally is considered conservative it can be seen from the data presented in this paper that this is not the case at person densities below $3 \mathrm{pers} / \mathrm{m}^{2}$, when it comes to children.

Evacuation models rarely consider children mainly due to lack of data and information on the field. This indicates that children's safety in buildings can be improved by providing the necessary data and knowledge on this important topic. More data is needed for further understanding on the subject and for future models to describe children's evacuation pattern and behavior.

\section{REFERENCES}

[1] Larusdottir, A.R. and Dederichs, A.S., (2010) Evacuation of Children: Movement on Stairs and on Horizontal Plane, Fire Technology special issue. http://dx.doi.org/10.1007/s10694-010-0177-6

[2] Nordic statistical Yearbook, Nordic Council of Ministers, Nordic Council, 2009.

[3] Building Bulleting 100: Design for fire safety in schools, Department for Children, Schools and Families, EC2P 2EA, RIBA Enterprises Ltd (NBS), London, 2007.

[4] Wermiel, S.E., The fire prove building, The Johnson University press, London, 2000.

[5] Sørensen, L.S., Brandfysik og brandteknisk design af bygninger, Politeknisk Forlag, 2004.

[6] Proulx, G., (1995) Evacuation time and movement in apartment buildings, Fire Safety Journal 24, 229-246, http://dx.doi.org/10.1016/0379-7112(95)00023-M

[7] Nelson, H. E and Mowrer, F.W., "Emergency Movement," The SFPE Handbook of Fire Protection Engineering ( $3^{\text {rd }}$ ed), DiNenno, P.J. and Walton, W.D. (ed), Society of Fire Protection Engineers, Bethesda, MD, 2002, pp. 3-367-3-380.

[8] Proulx, G., "Movement of People: The Evacuation Timing," The SFPE Handbook of Fire Protection Engineering ( $3^{\text {rd }}$ ed), DiNenno, P.J. and Walton, W.D. (ed), Society of Fire Protection Engineers, Bethesda, MD, 2002, pp. 3-341-3-366.

[9] Nilsson, D., "Exit choice in fire emergencies," Ph.D. thesis, Department of Fire Safety Engineering and Systems Safety, Lund, Sweden, 2009.

[10] Frantzich, H., "En modell för dimensionering av förbindelser för utrymning utifrån funktionsbaserede krav," Technical report 1011, Department of Fire Safety Engineering, Lund University, 1994.

[11] Frantzich, H., "Utrymningsvägars fysiska kapacitet, sammanställning och utvärdering av kunskapsläget," Technical Report 3069, Department of Fire Safety Engineering, Lund University, 1993.

[12] Proulx, G. and Reid, I.M.A., (2006) Occupant behavior and evacuation during the Chicago cook county administration building fire, Fire Protection Engineering 16: 283-309, http://dx.doi.org/10.1177/1042391506065951 
[13] Steffensen, F. B., "Brand og brandsikkerhed i forsamlingslokaler et fælles ansvar," Technical report, Københavns Brandvæsen, 2000.

[14] Ravn, K., "Undersøgelse af Reaktions- og Beslutningstid," Master thesis, Technical University of Denmark , 2008.

[15] Bryan, J. L., "Behavioral Response to Fire and Smoke," The SFPE Handbook of Fire Protection Engineering ( $\left.3^{\text {rd }} \mathrm{ed}\right)$, DiNenno, P.J. and Walton, W.D. (ed), Society of Fire Protection Engineers, Bethesda, MD, 2002, pp. 3-315-3-341.

[16] Predtechenskii, V.M. and Milinskii, A.I., Planning for Foot Traffic Flow in Buildings, Stroiizdat Publishers, Moscow, 1969.

[17] Shields, T.J., Smyth, B., Boyce, K.E. and Silcock, W.H., (1999) Towards the prediction of evacuation behaviours for people with learning difficulties, Facilities 17 (9/10): 336-344, http://dx.doi.org/10.1108/02632779910278746

[18] Nisser, M., "Utrymningssäkerhet för rörelsehindrade," Technical Report, Räddningsverket, Sverige, 2001.

[19] Gwynne, S.M.V., Boswell, D.L. and Proulx, G., (2009) Understanding the Effectiveness of Notification Technologies in Assisting Vulnerable Populations, Journal of Fire Protection Engineering 19: 31-48, http://dx.doi.org/10.1177/1042391508095094

[20] Bruck, D. and Thomas, I., (2008) Comparison of the Effectiveness of Different Fire Notification Signals in Sleeping Older Adults, Fire Technology 44: 15-38, http://dx.doi.org/10.1007/s10694$\underline{007-0017-5}$

[21] Bruck, D., (1999) Non-awakening in children in response to a smoke detector alarm, Fire Safety Journal 32 (4):369-376, http://dx.doi.org/10.1016/S0379-7112(98)00035-6

[22] Larusdottir, A.R. and Dederichs, A.S., "Evacuation dynamics of children: Walking speeds, flow through doors in daycare centers," Proceedings of the Fifth International Conference on Pedestrian and Evacuation Dynamics 2010, NIST, Gaithersburg, USA, 2010.

[23] Murozaki, Y. and Ohnishi, K. (1985) A study of fire safety and evacuation planning for preschools and day care centers, Memoirs of the Faculty of Engineering Kobe University 32: 99-109.

[24] Kholshevnikov,V.V., Samoshin, D.A. and Parfenenko, A.P., "Pre-School and School Children Building Evacuation," Proceedings of the Fourth International Symposium on Human Behaviour in Fire 2009, Robinson College, Cambridge, UK, 2009.

[25] Brandskyddshandboken, Rapport 3134, Department of Fire Safety Engineering, Lund University, 2005. 